\title{
Anaphylactic reactions to pomegranate: identification and characterization of eliciting lgE-reactive components
}

\author{
Arnd Petersen ${ }^{1 *}$, Andreas Kleinheinz ${ }^{2}$, Uta Jappe ${ }^{1}$ \\ From Food Allergy and Anaphylaxis Meeting 2011 \\ Venice, Italy. 17-19 February 2011
}

\section{Background}

Reports on anaphylactic reactions to exotic fruits, e.g. kiwi and dragon fruit, are increasing. Therefore, the allergenic risk assessment and the identification of allergenic components are important. 9 cases of allergic reactions to pomegranate have already been reported, but the responsible allergens have so far not been characterized in detail.

\section{Patients and methods}

A 26 year old female patient developed erythema, swelling of the ears and pruritus within $10 \mathrm{~min}$ after ingestion of pomegranate. She is allergic to birch pollen and apple. Prick and IgE tests revealed a positive reaction to mites, tree and grass pollen, ambrosia, mugwort and apple. Scratch test was positive for pomegranate, the seeds showing a stronger reaction than the juice. Oral provocation test with kiwi, peach and cherry was negative. The serum was analysed for IgE reactivity by Western blotting. As extracts served different sections of pomegranate (juice, extract and seed). IgE-reactive protein bands were analyzed and identified by protein sequencing and homology screening.

\section{Results}

The IgE-binding patterns differed between juice with one band of $9 \mathrm{kDa}$ and the seeds with three IgE-reactive components of about 21, 16 and $6 \mathrm{kDa}$. The $9 \mathrm{kDa}$ allergen was identified as a lipid transfer protein (LTP), which revealed a $77 \%$ sequence identity to the LTP from peach. While the $21 \mathrm{kDa}$ protein of the seeds was $\mathrm{N}$-terminally blocked, the $16 \mathrm{kDa}$ component showed

sequence similarity to Bet $\mathrm{v} 1$-homologous proteins, which is in line with the patient's reactivity to birch and apple. The $6 \mathrm{kDa}$ protein revealed no significant sequence similarities to proteins in the databases. Tryptic mass fingerprinting is in progress to identify the allergens in more detail.

\section{Conclusions}

Pomegranate is a relevant allergen source which shows different IgE-reactive components in its compartments. The structural characterization of these components is necessary to define their allergenicity and the underlying IgE-binding epitopes for improving in vivo and in vitro diagnosis and to estimate the potency of novel allergens in the future.

\section{Author details}

${ }^{1}$ Research Center Borstel, Clinical and Molecular Allergology, Borstel, Germany. ${ }^{2}$ Dermatological Center Buxtehude, Buxtehude, Germany.

Published: 12 August 2011

doi:10.1186/2045-7022-1-S1-P88

Cite this article as: Petersen et al: Anaphylactic reactions to pomegranate: identification and characterization of eliciting IgE-reactive components. Clinical and Translational Allergy 2011 1(Suppl 1):P88.

${ }^{1}$ Research Center Borstel, Clinical and Molecular Allergology, Borstel, Germany

Full list of author information is available at the end of the article

(c) 2011 Petersen et al; licensee BioMed Central Ltd. This is an open access article distributed under the terms of the Creative Commons 